\title{
HOW TO DELIVER INTEGRATED CARE
}




\title{
European Health Management in Transition
}

\author{
Series Editors:
}

Federico Lega, Full Professor of Health Management and Policy, Director of the Research and Executive Education Center in Health Administration, University of Milan

Usman Khan, Visiting Professor, KU Leuven

Healthcare is currently undergoing an unprecedented period of change, which is presenting a challenge to the fundamental tenants of health management and policy established over the last decades. The differentiated nature of the change agenda and the pace of change has been such that there has been limited space or time to provide a structured or comprehensive response, or to consider at a strategic level how health management teaching and practice should evolve and develop. This then is the focus for the European Health Management in Transition series, published in alliance with the European Health Management Association (EHMA).

Books in the series investigate how changes to the health and social care environment are leading to innovative and different practices in health management, health services delivery design, roles and professions, architecture and governance of health systems, patient engagement and all other paradigmatic shifts taking place in the health context.

The books provide a roadmap for managers, educators researchers and policy makers to better understand this rapidly developing environment. 
Books in the series:

Axel Kaehne and Henk Nies (eds): How to Deliver Integrated Care: A Guidebook for Managers

Federico Lega and Usman Khan: Health Management 2.0: Meeting the Challenge of 21st Century Health 
This page intentionally left blank 


\title{
HOW TO DELIVER \\ INTEGRATED CARE: A \\ GUIDEBOOK FOR MANAGERS
}

\author{
EDITED BY \\ AXEL KAEHNE \\ Edge Hill University, UK

\section{HENK NIES}

Vilans, Centre of Expertise for Long-term Care;

Vrije Universiteit, The Netherlands

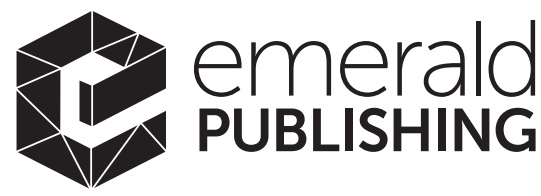

United Kingdom - North America - Japan - India Malaysia - China 
Emerald Publishing Limited

Howard House, Wagon Lane, Bingley BD16 1WA, UK

First edition 2021

Editorial matter and selection Copyright (C) 2021 Axel Kaehne and Henk Nies. Individual chapters $(C)$ their respective authors.

Published under exclusive licence by Emerald Publishing Limited.

\section{Reprints and permissions service}

Contact: permissions@emeraldinsight.com

No part of this book may be reproduced, stored in a retrieval system, transmitted in any form or by any means electronic, mechanical, photocopying, recording or otherwise without either the prior written permission of the publisher or a licence permitting restricted copying issued in the UK by The Copyright Licensing Agency and in the USA by The Copyright Clearance Center. Any opinions expressed in the chapters are those of the authors. Whilst Emerald makes every effort to ensure the quality and accuracy of its content, Emerald makes no representation implied or otherwise, as to the chapters' suitability and application and disclaims any warranties, express or implied, to their use.

\section{British Library Cataloguing in Publication Data}

A catalogue record for this book is available from the British Library

ISBN: 978-1-83867-530-1 (Print)

ISBN: 978-1-83867-527-1 (Online)

ISBN: 978-1-83867-529-5 (Epub)

ISOQAR certified

Management System,

awarded to Emerald

for adherence to

Environmental

standard

ISOQAR

ISO 14001:2004.

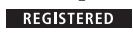

Certificate Number 1985

ISO 14001

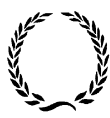

INVESTOR IN PEOPLE 


\section{TABLE OF CONTENTS}

List of Tables and Figures

List of Contributors

$x i$

About the Contributors

xiii

Foreword

xix

1. Integrated Care - An Introduction

Axel Kaehne and Henk Nies

2. Financing Care Integration: A Conceptual

Framework of Payment Models That Support Integrated Care

Eric van der Hijden and Jeroen van der Wolk

3. Leadership in Integrated Care

Helen Dickinson and Catherine Smith

4. Engaging Patients for Integrating Care

Rachael Smithson, Christina Wicker and Kimberley

Pierce

5. Social Dimensions of Care Integration

Karin Kee, Henk Nies, Marieke van Wieringen

and Bianca Beersma

6. Values in Integrated Care

Nick Zonneveld, Henk Nies, Elize van Wijk and Mirella Minkman 
7. Digital Health Enabling Integrated Care

Carolyn Steele Gray, Dominique Gagnon,

Nick Guldemond and Timothy Kenealy

8. Implementing Integrated Care

Axel Kaehne

9. Evaluating Integrated Care

Walter Wodchis, Carolyn Steele Gray, Jay Shaw,

Kerry Kuluski, Gayathri Embuldeniya, G. Ross

Baker and Maritt Kirst

Index 


\section{LIST OF TABLES AND FIGURES}

Table 2.1. Overview of Payment Models by Type of Integrator.

Table 3.1. IC Leadership Competencies.

Table 3.2. Desirable Personal Characteristics of IC Leaders.

Table 3.3. Mechanisms for Change in Complex Systems.

Table 7.1. Non-adoption, Abandonment, Scale-up, Spread and Sustainability Domains and Guiding Questions Adapted for Integrated Care.

Table 7.2. Recommendations for Implementing Digital Health Solutions in Integrated Care.

Table 9.1. Summary of Selected Evaluation Approaches.

Figure 1.1. Framework for Integrated Care.

Figure 3.1. Medical Leadership Competency Framework. 
Figure 3.2. Different Levels of Care Integration and Associated Leadership Styles and Tasks. $\quad 48$

Figure 4.1. Design Thinking Process. 63

Figure 4.2. Workshop and Validation Flowchart. 66

Figure 6.1. Value Mapping Exercise. 107

Figure 7.1. Digital Health Technologies to Support Components of Integrated Models.

Figure 7.2. Steps in User-centred Co-design of Technology.

Figure 8.1. Kotter's 8 Steps of Implementation. 146

Figure 9.1. Example Logic Model. 165

Figure 9.2. Summary of Evaluation Steps: The Evaluation Framework. 


\section{LIST OF CONTRIBUTORS}

G. Ross Baker University of Toronto, Canada

Bianca Beersma Vrije Universiteit Amsterdam, The Netherlands

Helen Dickinson University of New South Wales, Canberra, Australia

Gayathri

Embuldeniya University of Toronto, Canada

Dominique University of Québec, Abitibi-

Gagnon Témiscamingue, Canada

Nick Guldemond Sechenov First Moscow State Medical University, Russia and Leiden University Medical Center, The Netherlands

Axel Kaehne Edge Hill University, UK

Karin Kee Vrije Universiteit Amsterdam, The Netherlands

Timothy Kenealy University of Auckland, New Zealand

Maritt Kirst Wilfrid Laurier University, Canada

Carolyn Steele Sinai Health System and University of Gray Toronto, Canada 
Kerry Kuluski Trillium Health Partners and University of Toronto, Canada

Mirella Minkman Vilans, Centre of Expertise for Long-term Care and TIAS School for Business and Society, The Netherlands

Henk Nies

Vilans, Centre of Expertise for Long-term Care and Vrije Universiteit Amsterdam, The Netherlands

Kimberley Pierce Gold Coast Private Hospital, Australia Jay Shaw

Scientist, Women's College Hospital and University of Toronto, Canada

Catherine Smith University of Melbourne, Australia

Rachael Smithson Gold Coast Health and Griffith University, Australia

Eric van der Hijden Vrije Universiteit Amsterdam, The Netherlands

Jeroen van der Zilveren Kruis Health Insurance, The Wolk Netherlands

Marieke van Vrije Universiteit Amsterdam, The Wieringen Netherlands

Elize van Wijk Vilans, Centre of Expertise for Long-term Care, The Netherlands

Christina Wicker Gold Coast Health, Australia

Walter Wodchis University of Toronto and Trillium Health Partners, Canada

Nick Zonneveld Vilans, Centre of Expertise for Long-term Care and Tilburg University, The Netherlands 


\section{ABOUT THE CONTRIBUTORS}

G. Ross Baker is Professor in the Institute of Health Policy, Management and Evaluation at the University of Toronto and Program Lead in Quality Improvement and Patient Safety. His research includes studies of patient safety, teamwork, patient engagement and integrated care systems.

Bianca Beersma is Professor in Organizational Behavior and Theme Leader for Care and Welfare Research at the Institute for Societal Resilience at Vrije Universiteit Amsterdam. She is also Associate Editor for the Journal of Management. Her research interests include teamwork, informal communication, cooperation and conflict, and she studies these topics partly within the context of health care.

Helen Dickinson is Professor of Public Service Research and Director of the Public Service Research Group, University of New South Wales, Canberra, Australia. She is co-editor of the Journal of Health Organisation and Management and the Australian Journal of Public Administration. Her research interests revolve around policy implementation, with a particular focus on the health and disability fields.

Gayathri Embuldeniya is Qualitative Researcher at the University of Toronto's Institute of Health Policy, Management and Evaluation. She is a social scientist with research interests 
that include integrated health care models and patient and community engagement in health care and research.

Dominique Gagnon is Professor of Social Work at the University of Québec in Abitibi-Témiscamingue. His research interests include Integrated Community-Based Primary Health for the elderly and use of standardized clinical tools among providers.

Nick Guldemond is Professor of Integrated Care and Technology at Sechenov First Moscow State Medical University and Senior Researcher at the National eHealth Living Lab (NeLL) of Leiden University Medical Center. He holds a medical degree and a degree in electric engineering. During his career, he worked as a clinical researcher on numerous health innovation projects. He is a key expert for various governments, NGOs, multi-nationals and start-ups.

Axel Kaehne is Reader for Health Services Research at the Medical School at Edge Hill University, UK. He is also Editorin-Chief of the Journal of Integrated Care. His research interests include evaluating health care improvement programmes and implementation science. He is currently president of the European Health Management Association (EHMA).

Karin Kee is PhD candidate at VU Amsterdam. Her research interests include employee voice behaviour, occupational role identity and shared decision-making in healthcare.

Timothy Kenealy is medical general practitioner and Associate Professor of Integrated Care at the University of Auckland, New Zealand. His research often returns to improving care for diabetes and for long term conditions more generally. $\mathrm{He}$ currently co-leads an investigation into the associations between models of primary care delivery and patient outcomes. 
Maritt Kirst is Assistant Professor in the Department of Psychology at Wilfrid Laurier University. She has evaluated several complex health interventions including integrated care programs and Housing First programs.

Kerry Kuluski is Dr Mathias Gysler Research Chair in Patient and Family Centered Care at the Institute for Better Health at Trillium Health Partners and Associate Professor at the Institute of Health Policy, Management and Evaluation at the University of Toronto. Her research focuses on the health care experiences of older adults with complex care needs and their caregivers.

Mirella Minkman is Chief Executive Officer (CEO) at Vilans, Centre of Expertise for Long-term Care in the Netherlands. She is also Professor of Innovation of Organization and Governance of Integrated Care at Tilburg University/TIAS School for Business and Society. She is an Executive Board Member of the International Foundation of Integrated Care and the Chair of the National advisory and innovation Committee on governance in health care in the Netherlands.

Henk Nies is Director of Strategy and Development at Vilans, Centre of Expertise for Long-term Care in the Netherlands. He is also Endowed Professor at Vrije Universiteit Amsterdam and member of the Quality Council of the National Health Care Institute in the Netherlands. He has been involved in a number of national and European projects concerning integrated care.

Kimberley Pierce is the General Manager at Gold Coast Private Hospital, formally Chief Operating Officer at Gold Coast Health. She thoroughly enjoys working with great clinicians who have a vision to reform patient care and achieve world class clinical outcomes. 
Jay Shaw is Scientist at the Institute for Health System Solution and Virtual Care at Women's College Hospital, and is Director of Artificial Intelligence, Ethics \& Health at the University of Toronto Join Centre for Bioethics. He is StatusAppointed Assistant Professor in the Institute of Health Policy, Management and Evaluation at University of Toronto.

Catherine Smith is Lecturer in Education at the Graduate School of Education, University of Melbourne, Australia. Her work examines the role of care practices and policy in social justice.

Rachael Smithson is Research Director in the Transformation and Digital Division at Gold Coast Health, and Adjunct Associate Professor at Griffith University. Her research interests include system reform, governance and integrated care.

Carolyn Steele Gray is Scientist at the Bridgepoint Collaboratory for Research and Innovation in the Lunenfeld-Tanenbaum Research Institute at Sinai Health System in Toronto, Canada. She is also Assistant Professor at the Institute of Health Policy, Management and Evaluation at the University of Toronto. Her research program focuses on the development, implementation and evaluation of digital health solutions used in models of integrated community-based primary health care.

Eric van der Hijden is Project Leader of the research team; (financial) incentives for appropriate care at the Talma Institute of the Vrije Universiteit Amsterdam. He is also senior policy advisor health care procurement strategy and innovation at Zilveren Kruis Health Insurance in the Netherlands.

Jeroen van der Wolk is Senior Manager Healthcare Procurement Strategy and Analytics, Zilveren Kruis Health Insurance in the Netherlands. 
Marieke van Wieringen is Post-Doctoral Researcher at Vrije Universiteit Amsterdam. Her research interests include health care occupations (nurses), occupational role identity, development and change, and employee voice.

Elize van Wijk is Researcher and Advisor at Vilans, Centre of Expertise for Long-term Care in the Netherlands. She holds a Master's degree in Sociology with a specialization in Contemporary Social Problems and has been involved in projects on interdisciplinary collaboration in Integrated Dementia Care and Specialised Youth Care.

Christina Wicker is Director of the Integrated Care Alliance at Gold Coast Health. She has considerable international experience in managing large strategic healthcare projects.

Walter Wodchis is Professor at the Institute of Health Policy, Management and Evaluation at the University of Toronto and Research Chair in Implementation and Evaluation Science at the Institute for Better Health, Trillium Health Partners in Canada. He has led a number of large-scale integrated care research and evaluation studies.

Nick Zonneveld is Senior Researcher at Vilans, Centre of Expertise for Long-term Care in the Netherlands. He is also a $\mathrm{PhD}$ candidate at Tilburg University/TIAS School for Business and Society. He has been involved in a number of national and international projects on the organization and governance of integrated health and social care. 
This page intentionally left blank 


\section{FOREWORD}

\section{European Health Management in Transition}

When the discussion to develop this series on European Health Management in Transition began two years ago the world was a very different one to that which faces us as the first volume of the series is published. The seed for those early discussions emanated from the community of European health policy and management academics and practitioners, who regularly met under the auspices of the European Health Management Association. Established over forty years ago during the early days of collaborative European engagement on matters relating to health management and practice, discussion had turned to a consideration of how best to bring together current thinking in a form readily accessible to a policy, practitioner and academic audience.

On the basis of the value of collaborative European engagement and exchange having been established, our series provides a platform to consider how this prism maybe used to highlight how health management could best respond to this rapidly evolving health policy arena; the underpinning contention being that in order to successfully respond to the dynamics of a rapidly evolving health policy environment, health management systems and processes must rapidly evolve. The rationale for such thinking stems from the contention that health management evolved out of the systems of health 
administration introduced in the post war period to support the substantive widening of publicly funded healthcare. Hence, while health management was evidently more dynamic and purposeful in form, the connector between them was that both were orientated around the same predict and provide public service model, where the parameters of economic growth, sociodemographic change and health need were to a greater extent linear and foreseeable.

Such assumptions held for a period, but came to be challenged as the balance between infectious and noncommunicable disease tipped firmly towards the latter; manifest not only through well-established post war trends relating to smoking, cancer and coronary heart disease, but latterly with obesity, diabetes and Alzheimer's disease accounting for a greater proportion of health need. The complex, multi sectoral and interdisciplinary nature of need did not lend itself well to single domain management practice, versed at it is in the centrality of the hospital and the healthcare professional. This is not to say that the discipline of health management has not offered significant value to those seeking to establish efficient and effective health systems, able to meet fundamental population health need. Rather as the new century replaced the old, it was becoming increasingly apparent that traditional health management practice, was finding the challenge of delivering patient centred value-based healthcare a significant one.

Developments within health systems, as the planning, organizing and delivering of health services were experiencing a never before achieved level of complexity and challenge. Population health management and medicine of initiative are substituting the traditional 'reactive' posture of medical environment. Co-creation and co-production of services are replacing the notion of patient empowerment. Integrated care, from a sterile discussion among academics and policy-makers, 
has morphed into managed clinical networks, hub \& spokes systems, hot \& cold structural solutions, multi-discipline and multi-professional clinical services lines, and much more. Less 'shuffling boxes around', more management on the 'shop floor'. New professions are gaining turf as the hierarchical relationship between doctors and rest of the health professionals is slowly but steadily moving toward a more horizontal positioning.

Doctor-manager roles are reconfigured toward clinicalleaders, as health systems are aware that sustainability is not just a matter of controlling costs, but rather an exercise of priority-setting, engagement and collective and individual accountability. Universalism is now widely re-conceptualized in selective universalism. Universal Payer systems are moving quickly toward mixed systems, with increasing levels of health care intermediated by private third payors. Health services consumerism is reality, if not a want of patients. For sure, it's not any more an ideological or abstract thinking. Hence, health management is more central than ever, being pivotal to this revolution.

Additionally, we have the poignant irony of the COVID-19 pandemic, as a twenty-first century manifestation of the type of public health calamity that had been thought to have been consigned to a chapter of medical social history, returns to further challenge the fundamental tenants of traditional healthcare management. Equally, whilst many aspects of the health management response to the pandemic were highly laudable, it has also been evident that traditional health management often appeared to lack the flexibility necessary to respond to medial and political direction efficiently and effectively.

The European Health Management in Transition Series tackles all the 'disruptive' changes that are re-framing the way management needs to develop within health systems and 
organizations. It includes a scene setting volume, which sets health management practice to be at a turning point. This imagining of European health systems facing a dynamic and rapidly evolving need profile, fuelling a radical change in health management practice, forms then the central horizontal pillar of the Series. Rest of the volumes of the series then consider how the principal domains of health policy and practice are evolving in the light of these changes. Themes identified as vertical columns in the wider structures of modern day health and social care are integrated care, patient engagement, personalization and value based care, digital health and the future governance of health systems.

The European Health Management in Transition series comes then at a timely juncture. Health systems are having to rapidly respond to the now common notion of the new normal, where the challenge of meeting the real and present danger of the existing pandemic continuing to impact on healthcare for the foreseeable future. Combined with the challenge of non-communicable disease remaining in the health policy 'pending tray', leaves today's healthcare manager seeing challenge coming from every side. Our Series will address these challenges head on, providing foundations to frame the new context and adopting a forward (and lateral) looking perspective in order to help those working in this field to more fully understand and to be better prepared to respond to these challenges ahead. 